\section{Out of Bounds. Medicine and the Hundred Acre Wood}

Richard V. Lee, MD, MACP, FRGS

Royal Society of Medicine Press Ltd., 2013

ISBN 978-1-85315-983-1

Distribution in Europe and Rest of World:

Marston Book Services Ltd., PO Box 269,

Abingdon. Oxon OX14 4YN, UK.

Email: direct.order@marston.com

Website: www.rsmpress.co.uk

En este libro el autor compiló su vida como clínico, salubrista, epidemiólogo, historiador, investigador y filósofo de la medicina. En la contratapa figura el siguiente comentario, traducido del inglés por el responsable de dicho comentario:

"Richard V. Lee nació y creció en un país vasto y altamente desarrollado, que le ofrecía horizontes muy amplios para vivir. Pero se sintió compelido a expandir estos horizontes al mundo entero. $\mathrm{Su}$ libro es una herencia que nos recuerda la vida, el pensamiento y las aventuras de un hombre muy especial.

Siendo tanto un especialista como un generalista, Dick supo aprovechar los descubrimientos científicos y las novedades tecnológicas que han revolucionado la medicina en décadas recientes, comunicarse con la gente, diagnosticar enfermedades y aconsejar sobre su tratamiento.

El libro nos da ejemplos de cómo el progreso médico y la práctica clínica pueden fusionarse con la comprensión de la cultura y el ambiente, como condicionantes de la forma de vida y el estado de salud en lugares tan distintos como los Himalayas, los Andes, la Amazonía brasilera, los desiertos en África y aldeas en Asia. El significado de la solidaridad y la compasión en medicina se expresan como su mensaje primordial.

Además de ser un médico, el Profesor Lee fue un sabio, un maestro, un escritor, un hombre para todas las épocas y latitudes, capaz de deleitar a una

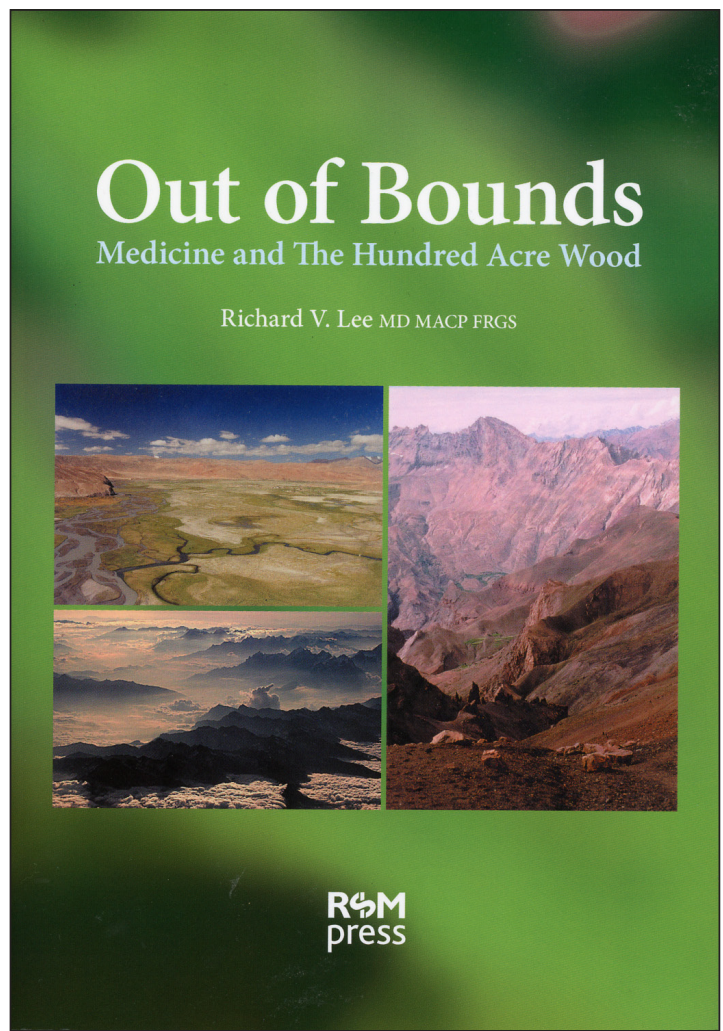

gran audiencia dando la conferencia de clausura en un Congreso Mundial de Medicina Interna o capturando la atención de jóvenes estudiantes en una escuela de medicina muy alejada de su país natal."

Recomendamos la lectura de esta obra a estudiantes de medicina, profesionales de la salud y educadores en estas profesiones. Para facilitar su adquisición se anotaron los datos postales y de internet correspondientes.

Humberto Reyes B.

Profesor Emérito, Universidad de Chile. Miembro de Número de la Academia Chilena de Medicina.

Editor de la Revista Médica de Chile. 